1

\section{ABOUT THE LUMPED PARAMETER APPROACH TO HYDRAULIC}

LINE MODELLING

By

Galal RABIE*

\title{
ABSTRACT
}

This paper deals with the development of simple lumped models of hydraulic transmission 1ine. The models take into consideration the effect of viscous damping, fluid inertia, fluid compressibility and elasticity of line material. The developed models are one-directional;the fluid speed and pressure are thought of as averaged quantities over the cross section of the line. The simplicity of models result from the seperate evaluation of the effect of the above mentioned parameters. The validity of the models is discussed on the bases of the comparison of the step and frequency responses of models with experimental results.

* Lecturer, Chair of Aircraft, Military Technical College, Cairo. 
1. Int roduction

Hydraulic transmission lines are basic elements in Hydraulic systems. They are applied to communicate hydraulic power between the individual elements. Generally, the dynamics of these lines can't by neglected, specially in the hydraulic control systems, where high power and quick response are required.

The dynamic behaviour of hydraulic lines has been the subject of numerous studies $|1|$ to $|9|$. In their papers, D'SOUZA \& OLDENBERGER $|3|$, GOODSON \& LEONARD $|5|$, LALLEMENT $|7|$ and DOEBLIN $|9|$, have developed distributed parameter models considering the variation of the speed and pressure in both axial and radial directions. These models consist of a system of partial differential equations.

When using the lumped parameter approach, considering averaged variables along the radial direction, the partial differential equations are replaced by ordinary differential equations $|1|,|2|$ and $|9|$. The treatement of these equations lead to a transfer matrix relating the flow and pressure at both extremities of the line. The transfer matrix includes hyperbolic functions of the Laplace operator; 5 .

The resulting transfer functions of line are trancendental in $s$. The computation of frequency response from such models is simple, but serious mathematical difficulties are encountered whencomputing line transients. The standard techniques of expanding the functions in power series yield characteristic equations with negative coefficients implying system instability where it does not actually occur $|3|$.

These models may be convenient for the study of the transmission line itself ; as a system. But when studying a hydraulic control system, including several transmission lines, the application of such models results in highly complicated models, difficult to be treated mathematically or numerically.

We have to look then for a simple model, the application of which does not complicate the global model of the system. An idea of such a model is presented by KARNOPP $|6|$.

\section{DEVEloppment of LUMPED PARAMETER MODELS}

The models, proposed in this paper, take into consideration the effect of the viscous damping, inertia of the fluid column, compressibility of the fluid and elasticity of pipe walls. The flow in the line is considered as one-dimensional flow. The fluid speed, $v$, and pressure, $p$, are thought of as averaged quantities over a field of velocities and pressures which vary over the cross-sectional area. The fluid is assumed to move as one lump subjected to the above mentioned effects.

Aiming to evaluate seperately the effect of these parameters, let us imagine that the line is divided into three portions, Fig. 1. The effect of the resistance of the whole $l \mathrm{ind}$ is local ized in the first portion, the effect of the inertia of the fluid is localized in the second portion, where as the effect of fluid compressibility and elasticity of material takes place in the third portion. 
$\Gamma$

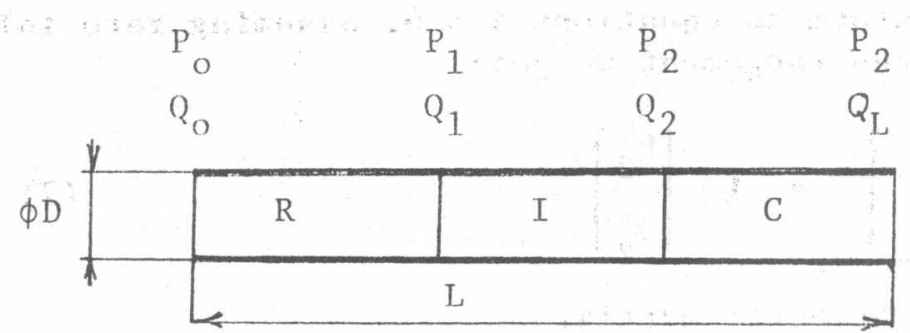

Fig.2 . Scheme of hyd. Line.

\subsection{Line resistance}

The first portion of line simulates only the effect of line resistance due to viscous friction, thus the flow every where is equal in this portion.

$Q_{0}=Q_{1}$

Assuming laminar flow, the pressure drop due to viscous friction is given by

$\mathrm{p}_{0}-\mathrm{p}_{1}=\frac{128 \mu L}{\pi \cdot \mathrm{D}^{4}} \quad \mathrm{Q}_{0}=R \mathrm{Q}_{\mathrm{O}}$

Where $R$ is the line resistance. Applying Laplace's transform to equations $1 \& 2$, then after rearrangement one gets:

$\left[\begin{array}{l}P_{0}(s) \\ Q_{0}(s)\end{array}\right]=\left[\begin{array}{ll}1 & R \\ 0 & 1\end{array}\right]\left[\begin{array}{c}P_{1}(s) \\ Q_{1}(s)\end{array}\right]=\mathbb{R}\left[\begin{array}{c}P_{1} \\ Q_{1}\end{array}\right]$

Where $\mathbb{R}$ is the resistance transfer matrix.

\subsection{Line inertia}

Assuming that the fluid in the second portion is accelerated as one lump, then

$\mathrm{Q}_{1}=\mathrm{Q}_{2}$

Applying the second low of Newton to the accelerated mass of 1 luid;

$$
\begin{aligned}
& F=m \frac{d v}{d t} \quad ; F=\frac{\pi}{4} D^{2}\left(P_{1}-P_{2}\right) \\
& m=\frac{\pi}{4} D^{2} \rho L \\
& v=\frac{4}{\pi D^{2}} Q
\end{aligned}
$$

Then substituting for $F, m$ and $v$, equation 5 becomes :

$$
P_{1}-P_{2}=\frac{4 \rho L}{\pi D^{2}} \quad \frac{d Q}{d t}=I \frac{d Q}{d t}
$$

Where $I$ is the inertia of the fluid.

This expression for the fluid inertia is convenient when replacing the effort and flow variables of the mechanics of translation; Fand $v$, by those of mechanics of fluids $p$ and $Q$. 
Applying Laplace's transform to equations $4 \& 6$, assuming zero initial conditions, then after rearrangement we get:

$$
\left[\begin{array}{l}
\mathrm{P}_{1} \\
\mathrm{Q}_{1}
\end{array}\right]=\left[\begin{array}{cc}
1 & \mathrm{I} \mathbf{s} \\
0 & 1
\end{array}\right]\left[\begin{array}{l}
\mathrm{P}_{2} \\
\mathrm{Q}_{2}
\end{array}\right]=\mathbf{I}\left[\begin{array}{l}
\mathrm{P}_{2} \\
\mathrm{Q}_{2}
\end{array}\right]
$$

Where $\mathbb{I}$ is the inertia transfer matrix.

\subsection{Line capacitance}

In the third portion, where only the effect of fluid compressibility and line material elasticity,are assumed to take place, the pressure every where is the same;

$$
\mathrm{P}_{2}=\mathrm{P}_{\mathrm{L}}
$$

But the input flow $Q_{2}$ differes from the output $\mathrm{flow}_{\mathrm{L}}$ by the flow due to compressibility; $Q_{c}$, which is given by:

$$
Q_{C}=\frac{V}{B} \frac{{ }^{P}}{P_{2}}
$$

If the deformation of pipe material is to be taken into consideration, then this relation becomes:

$$
\mathrm{Q}_{\mathrm{C}}=\mathrm{V}\left(\frac{1}{\mathrm{~B}}+\frac{\mathrm{D}}{\mathrm{Eh}}\right) \frac{\mathrm{dP} 2}{\mathrm{dt}}=\frac{\mathrm{V}}{\mathrm{B}_{\mathrm{e}}} \frac{\mathrm{dP} 2}{\mathrm{dt}}
$$

Where $B_{e}$ is the equivelent bulk moduls.

The effect of fluid compressibility, which is conservative of energy, is described mathematically by a relation analogous to that describing the electric capacitance; $i=\mathrm{C}$ de/dt. The hydraulic capacitance is thus defined, on the basis of equation 10, by:

$$
\mathrm{C}=\mathrm{V} / \mathrm{B}_{\mathrm{e}}
$$

Then $Q_{2}-Q_{L}=C \frac{d P}{d t}$

Applying Laplace's transform to equations $8 \& 12$, then after rearrangement one gets:

$$
\left|\begin{array}{l}
\mathrm{P}_{2} \\
\mathrm{Q}_{2}
\end{array}\right|=\left|\begin{array}{cc}
1 & 0 \\
\mathrm{CS}_{S} & 1
\end{array}\right|\left|\begin{array}{c}
\mathrm{P}_{\mathrm{L}} \\
\mathrm{C}_{\mathrm{L}}
\end{array}\right|=\mathbf{C}\left|\begin{array}{c}
\mathrm{P}_{\mathrm{L}} \\
\mathrm{C}_{\mathrm{L}}
\end{array}\right|
$$

Where $\mathbf{C}$ is the capacitance transfer matrix

\subsection{Transfer matrix of a single lump model}

The transfer matrix of line, $\mathbb{A}$, can be obtained from equations 3,7 and 13 by the elimination of $\mathrm{P}_{1}, \mathrm{Q}_{1}, \mathrm{P}_{2}$ and $\mathrm{Q}_{2}$.

$$
\left[\begin{array}{l}
P_{0} \\
Q_{0}
\end{array}\right]=\mathbb{R} \pi \mathbb{C} \quad\left[\begin{array}{c}
P_{L} \\
\mathrm{P}_{L}
\end{array}\right]=\mathbb{A} \quad\left[\begin{array}{c}
P_{L} \\
Q_{L}
\end{array}\right]
$$


where $\mathbb{A}=\left[\begin{array}{cc}\mathrm{IC} \mathrm{s}^{2}+\mathrm{RCs}+1 & \mathrm{Is+R} \\ \mathrm{Cs} & 1\end{array}\right]$

This transfer matrix represents the line, assuming that the fluid is moving as one lump.

\subsection{Representation of line by more than one lump models :}

The fluid may be assumed to move in several lumps. In order to find the convenient number of lumps representing a line with sufficientaccuracy, let us derive the transfer matrix of line represented by different number of lumps considering the line with the fluid moving in two lumps, Fig. 2 . the elements R, I and $\mathrm{C}$ will be given by

$$
\begin{aligned}
& \mathrm{R}=\frac{128 \mu \mathrm{L} / 2}{\pi \mathrm{D}^{4}}, I=\frac{4 \rho \mathrm{L} / 2}{\pi \mathrm{D}^{2}} \text { and } \mathrm{C}=\frac{\pi \mathrm{D}^{2} \mathrm{~L} / 2}{4 \mathrm{~B}_{\mathrm{e}}} \\
& \begin{array}{|l|l|l|l|l|l|}
\hline \mathrm{R} & \mathrm{I} & \mathrm{C} & \mathrm{R} & \mathrm{I} & \mathrm{C} \\
\hline
\end{array} \\
& \begin{array}{|l|l|l|}
\mathrm{P}_{\mathrm{O}} \\
\hline
\end{array}
\end{aligned}
$$

Fig.2. Scheme of line with two fluid lumps.

The line is thus described by

$$
\left|\begin{array}{c}
\mathrm{P}_{\mathrm{O}} \\
\mathrm{Q}_{\mathrm{O}}
\end{array}\right|=\left[\begin{array}{lll}
\mathbb{R} & \mathbb{I} & \mathbf{C}
\end{array}\right]^{2}\left|\begin{array}{c}
\mathrm{P}_{\mathrm{L}} \\
\mathrm{Q}_{\mathrm{L}}
\end{array}\right|=\mathbb{A}_{2}\left|\begin{array}{c}
\mathrm{P}_{\mathrm{L}} \\
\mathrm{Q}_{\mathrm{L}}
\end{array}\right|
$$

where $\mathbb{A}_{2}=\left|\begin{array}{ll}\mathrm{a}_{11} & \mathrm{a}_{12} \\ \mathrm{a}_{21} & \mathrm{a}_{22}\end{array}\right|$

and $a_{I I}=I^{2} C^{2} s^{4}+2 I R C^{2} s^{3}+\left(R^{2} C^{2}+3 I C\right) s^{2}+3 R C s+1$

$$
\begin{aligned}
& \mathrm{a}_{12}=\mathrm{I}^{2} \mathrm{C} \mathrm{s}^{3}+3 I R C \mathrm{~s}^{2}+\left(\mathrm{R}^{2} \mathrm{C}+2 \mathrm{I}\right) \mathrm{s}+2 \mathrm{R} \\
& \mathrm{a}_{21}=I \mathrm{C}^{2} \mathrm{~s}^{3}+\mathrm{RC}^{2} \mathrm{~s}^{2}+2 \mathrm{Cs} \\
& \mathrm{a}_{22}=I \mathrm{C} \mathrm{s}^{2}+\mathrm{RC} \mathrm{s}+1
\end{aligned}
$$

The representation of line by three lumps results in a model of the form:

$$
\left|\begin{array}{l}
\mathrm{P}_{0} \\
\mathrm{Q}_{\mathrm{O}}
\end{array}\right|=\left[\begin{array}{lll}
\mathbb{R} & \mathbb{I} & \mathbf{C}
\end{array}\right]^{3} \quad\left|\begin{array}{c}
\mathrm{P}_{\mathrm{L}} \\
\mathrm{Q}_{\mathrm{L}}
\end{array}\right|=\mathrm{A}_{3}\left|\begin{array}{c}
\mathrm{P}_{\mathrm{L}} \\
\mathrm{Q}_{\mathrm{L}}
\end{array}\right|
$$

where the elements $R$, I and $C$ are given by

$$
R=\frac{128 \mu L / 3}{\pi D^{4}} ; I=\frac{4 \rho L / 3}{\pi D^{2}} \text { and } C=\frac{\pi D^{2} L / 3}{4 B e}
$$


The element $a_{11}$ of matrix $\mathbb{A}_{3}$ is given by

$$
\begin{aligned}
a_{11}= & I^{3} C^{3} s^{6}+3 I^{2} R C^{3} s^{5}+\left(3 I R^{2} C^{3}+5 I^{2} C^{2}\right) s^{4}+ \\
& \left(10 I R C^{2}+R^{3} C^{3}\right) s^{3}+\left(6 I C+5 R^{2} C^{2}\right) s^{2}+6 R C s+1
\end{aligned}
$$

If the line is represented by four lumps, then it can be described by:

$$
\begin{aligned}
& {\left[\begin{array}{l}
P_{0} \\
Q_{0}
\end{array}\right]=\left[\begin{array}{lll}
R & I I & C
\end{array}\right]^{4}\left[\begin{array}{c}
P_{L} \\
Q_{L}
\end{array}\right]=A_{4}\left[\begin{array}{c}
P_{L} \\
Q_{L}
\end{array}\right]} \\
& R=\frac{128 \mu}{\pi D^{4}} \frac{L}{4}, I=\frac{4 \rho}{\pi D^{2}} \frac{L}{4} \& C=\frac{\pi D^{2}}{4 B} \frac{L}{4}
\end{aligned}
$$

The element $a_{11}$ of matrix $\mathbb{A}_{4}$ is given by

$$
\begin{aligned}
a_{11}= & I^{4} C^{4} s^{8}+4 I^{3} R C^{4} S^{7}+\left(6 I^{2} R^{2} C^{4}+7 I^{3} C^{3}\right) S^{6}+ \\
& \left(21 I^{2} R C^{3}+4 I R^{3} C^{4}\right) s^{5}+\left(15 I^{2} C^{2}+21 I R^{2} C^{3}+R^{4} C^{4}\right) s^{4}+ \\
& \left(7 R^{3} C^{3}+30 I R C^{2}\right) s^{3}+\left(15 R^{2} C^{2}+10 I C\right) s^{2}+10 R C+1
\end{aligned}
$$

3. Modelling of the line by bond graph:

The representation of line by $\mathrm{R}, \mathrm{I}$ and $\mathrm{C}$ elements is convenient for the development of bond graph model of the line, Fig.3. The resistance and inertia, which have the same flow, are connected by a series, 1, junction, while the capacitance is connected to a common pressure, parallel, 0 junction. The expressions for $R, I$ and $C$ are given by equations 2,6 and 11 respectively.



Fig.3. Bond graph of line with one fluid lump.

The equations describing the line can be deduced systematically from the bond graph after the assignement of causality;augmented bond graph, Fig. 4 . The determination of the boundary conditions is essential for assignement of causality. In case of line closed at its end witha pressure source at the input, a source of flow, SF, imposes zero flow at the line end and a source of effort, $\mathrm{SE}$, imposes the pressure at the input to the 1ine. 
\begin{tabular}{|l|l|}
\hline DYN -4 & 37
\end{tabular}

SECOND A.M.E. CONFERENCE

6 - 8 May 1986 , Cairo

$r$



Fig.4. Augmented bond graph of the line.

The following equations are those describing the 1ine, obtained from the bond graph

$$
\begin{aligned}
\Delta P_{R} & =R Q_{O} \\
\Delta P_{I} & =P_{0}-\Delta P_{R}-P_{L} \\
Q_{O} & =Q_{O}(0)+\frac{1}{I} \int \Delta P_{I} d t \\
Q_{C} & =Q_{O}-Q_{L} \\
P_{L} & =P_{L}(0)+\frac{1}{c} \int Q_{C} d t
\end{aligned}
$$

If the line is to have n lumps of fluid, then its bond graph, Fig.5, will include $\mathrm{n}$ repeatitions of $\mathrm{Fig} .3$.

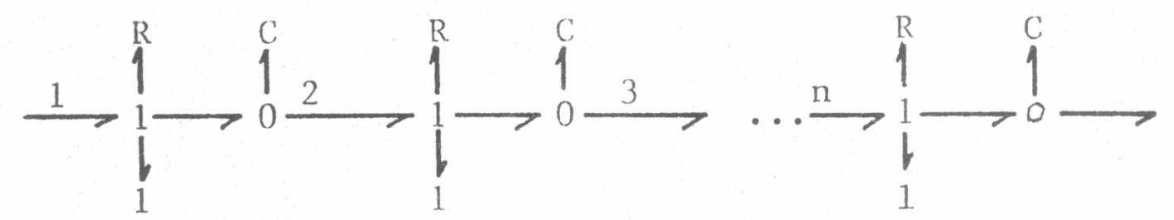

Fig.5. Bond graph of line with n lumps.

where

$$
R=\frac{12 \mu}{\pi D^{4}} \frac{L}{n}, I=\frac{4 \rho}{\pi D^{2}} \frac{L}{n} \text { and } C=\frac{\pi D^{2}}{B_{e}} \frac{L}{n}
$$

The above developed models are linear due to the assumption of 1 aminar flow. In the case of turbulent flow, the linear equation (26) describing the relation between effort and flow variables of the resistive element can be replaced by

$$
\Delta P_{R}=\lambda \frac{L}{n} \frac{8}{\pi^{2} D^{5}} Q_{O}^{2}
$$

where $\lambda=0,3164 \mathrm{R}_{\mathrm{e}}^{-0.25}$

4. Validity of the proposed models :

The validity of the proposed models is tested by comparing the response of the line with the experimental results published by Lallement|7|, for two different lines. The parameteres of lines are given in the following table. 
\begin{tabular}{|l|l|}
\hline DYN -4 & 38 \\
\hline
\end{tabular}

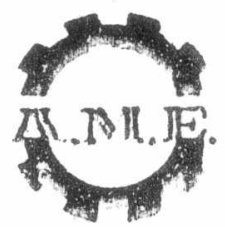

SECOND A.M.E. CONFERENCE

6 - 8 May 1986 , Cairo

\begin{tabular}{|l|l|l|}
\hline Parameter & Line 1 & Line 2. \\
\hline Length; $|\mathrm{m}|$ & 18 & 6 \\
Inner diameter ; $\phi \mathrm{D}|\mathrm{mm}|$ & 10 & 10 \\
Specific mass of fluidy $\left|\mathrm{k}_{\mathrm{g}}\right| 1$ & 868 & 868 \\
Kinematic viscosity of fluid ; $|\mathrm{Cs}|$ & 56 & 140 \\
Equivalent bulk modulus;Be $\left|\mathrm{P}_{\mathrm{a}}\right|$ & $1.610^{6}$ & $1.610^{9}$ \\
\hline
\end{tabular}

In the frequency domain, the frequency responses of the models is calcu1ated for the lines closed at one end and excited by a source of oscillating pressure at the other end.

The transfer function relating the pressures at both extremities of line can be obtained from the transfer matrix considering $Q_{L}=0$. A line represented by one lump;single $\mathrm{R}, \mathrm{C} \& \mathrm{I}$ elements, has the following transfer function, from eq. 15.

$$
\frac{\mathrm{P}_{\mathrm{L}}}{\mathrm{P}_{\mathrm{O}}}=\frac{1}{\mathrm{IC} \mathrm{S} 2+\mathrm{RC} \mathrm{s}+1}
$$

where R, I \& C are given by equations 2,6 and 11. The natural frequency and damping coefficient of the system are found, from this transfer function, to be :

$$
\omega_{n}=\frac{1}{L} \sqrt{\frac{B}{\rho}} \quad \& \xi=\frac{16 \mu L}{D^{2}} / \sqrt{\rho B e}
$$

When representing the line by two lumps, then from equations 17, 18 and 19, the transfer function of line becomes :

$$
\frac{P_{L}}{P_{0}}=\frac{1}{I^{2} C^{2} s^{4}+3 I R C^{2} s^{3}+\left(R^{2} C^{2}+3 I C\right) s^{2}+3 R C s+1}
$$
form :

A line represented by 3 lumps will have a transfer function of the

$$
\frac{P_{L}}{P_{O}}=\frac{1}{H(s)}
$$
Where the polynomial $\mathrm{H}(\mathrm{s})$ is the element $\mathrm{a}_{11}$ of the matrix $\mathbb{A}_{3}$, given by
equation 22 .

The representation of line by four lumps gives a transfer function of the same form, but the polynomial $11(s)$ will be the element a 11 of the matrix $\mathbb{A}_{4}$, given by equation 25 . and 9 .

The theoretical and experimental results are plotted in figures $6,7,8$

The representation of line by one lump results in a single resonance mode as shown in Fig. 6 and 8 . The model $1^{\text {has }}$ reater damping compared with the experimental results. The resonance frequency of model is lower than that found out experimentaly by about $29.3 \%$, for both of tested 1 ines. Thus, 


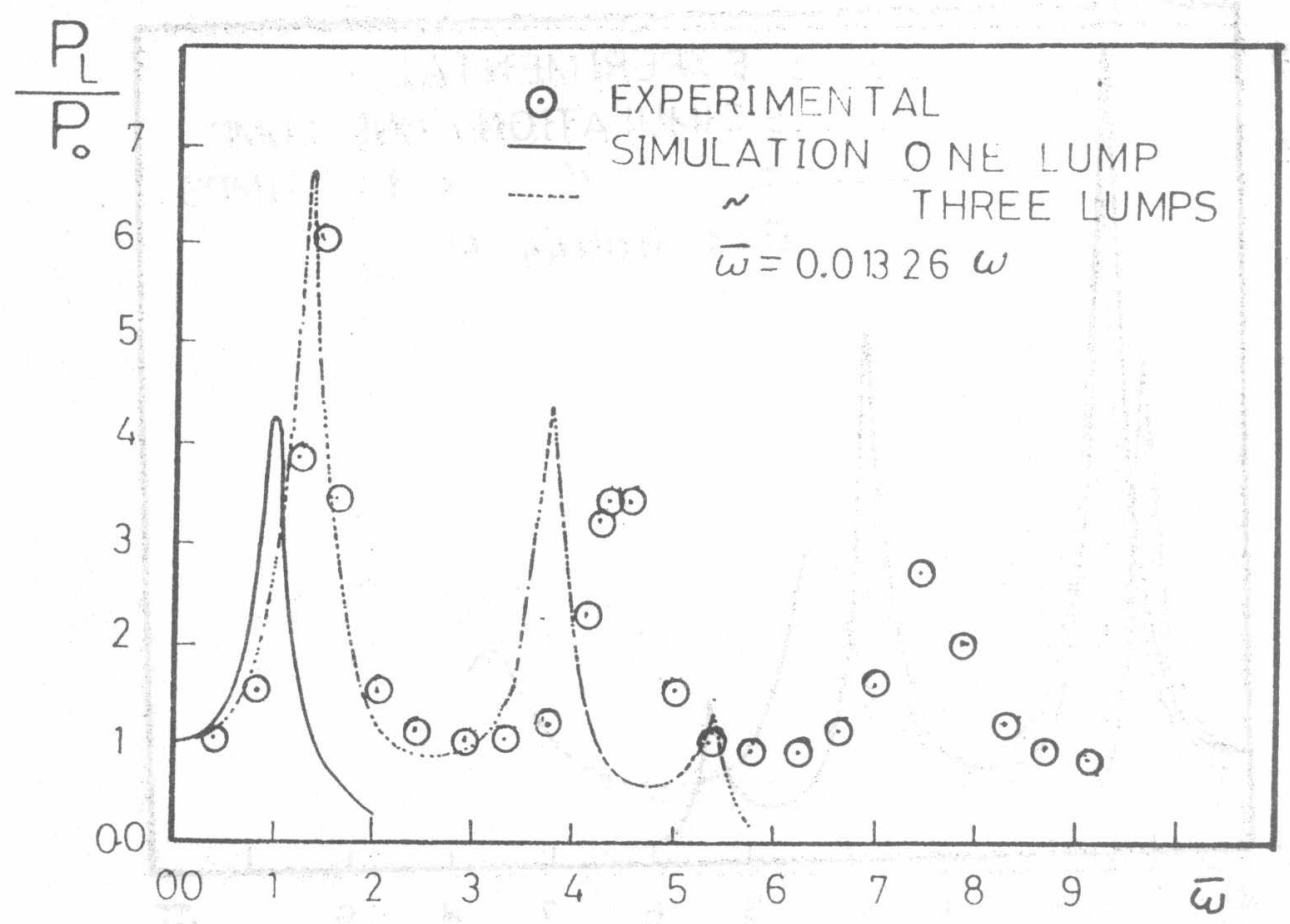

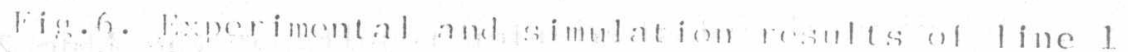
frequency rosponse evaluation, $n=1$ \& 3 . $\bar{\omega}=\mathrm{L} \omega / \mathrm{c} ; \mathrm{c}$ is the sound speed.

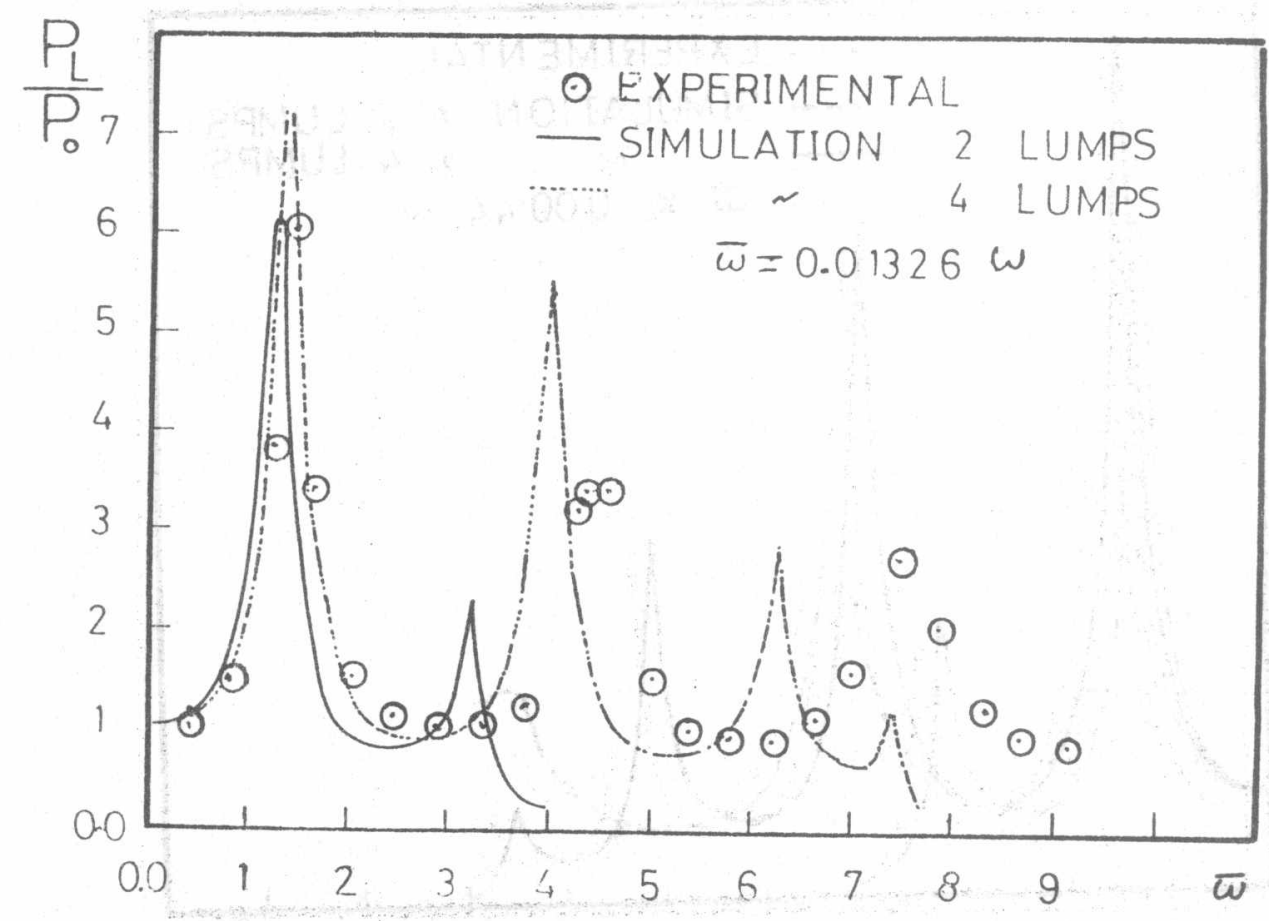

Fig.7. Esporimontal and simulation rosults of line 1 frequene? response evaluat ion of , $n=2$ \& 4 . 




Fis.a. Fepreimental and simmlat ion rosults of the line 2

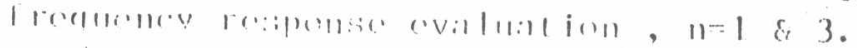

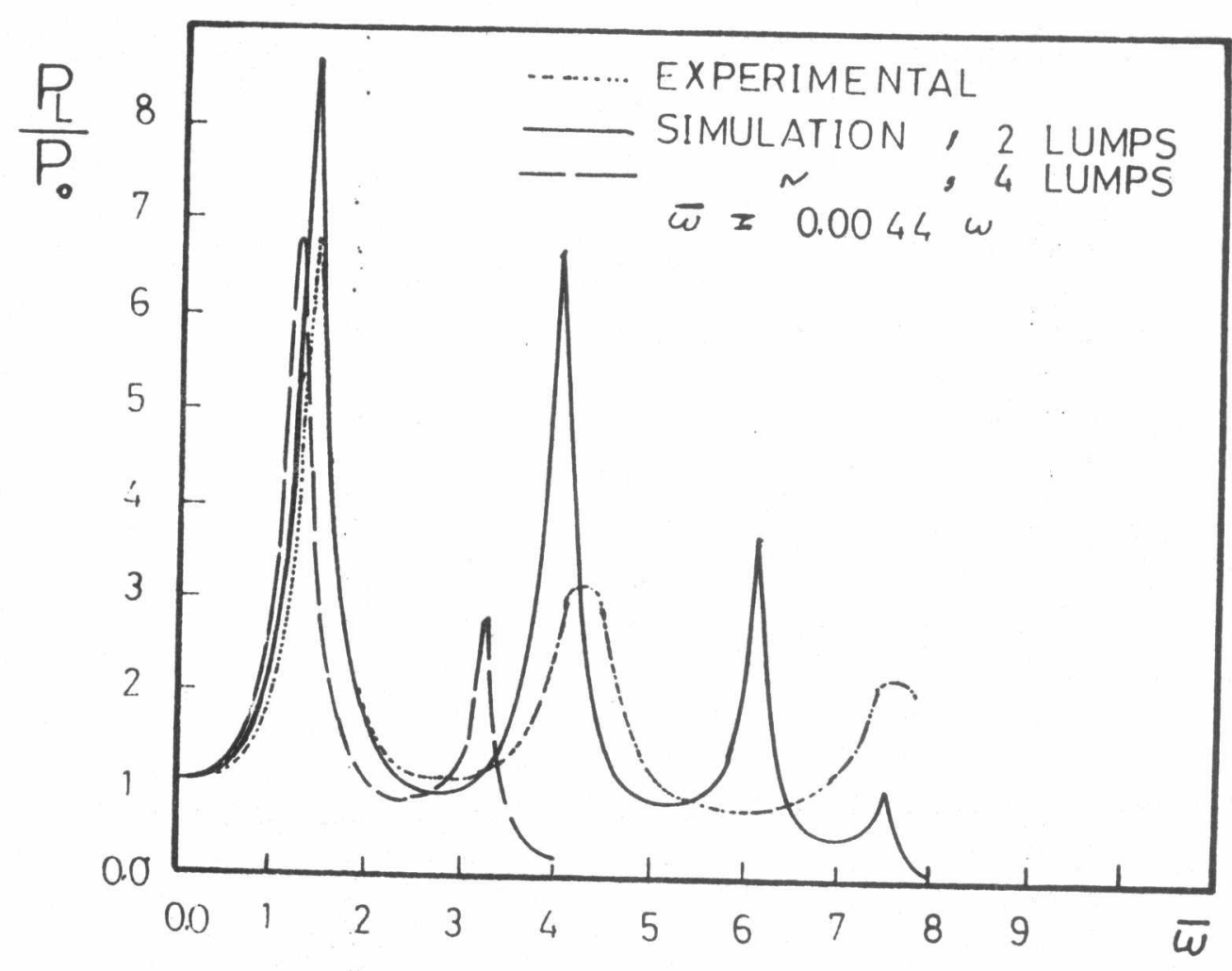

1is.9. Bunpinental and simulation results of the line 2 frepuene response cviluation, $n=2$ \& 4 . 
the frequency of the first mode of resonance of the real line can be predicted, on the basis of these results by the relation,

$$
\omega_{n 1}=\frac{1.413}{\mathrm{~L}} \vee \frac{\mathrm{B}_{\mathrm{e}}}{\rho}
$$

The representation of the line by two lumps leads to a two-degree of freedom system, having two resonance modes; Fig. 7 and 9 . The first resonance frequency approaches the experimental value; $\omega_{1} / \omega=0.88$, and the magnitude ratio comes very close to the experimentaf results.

The modeling of line by three and four fluid lumps results in three and four modes of resonance respectively. A summary of results of the frequency response of line 1 is given in table 1 . The resonance frequencies and damping coefficients of the different modes are extracted from the transfer functions by the calculation of their partial fractions.

\begin{tabular}{|c|c|c|c|c|c|c|c|c|}
\hline \multirow{2}{*}{$\begin{array}{l}\mathrm{Nr} \text { of } \\
\text { Lumps }\end{array}$} & \multicolumn{2}{|c|}{$1^{\mathrm{st}} \operatorname{mode}$} & \multicolumn{2}{|c|}{$2^{\text {nd }}$ mode } & \multicolumn{2}{|l|}{$3^{r d}$ mode } & \multicolumn{2}{|l|}{4 mode } \\
\hline & $\omega_{1} \omega_{n 1}$ & $\xi_{1}$ & $\omega_{2} / \omega_{n 2}$ & $\xi_{2}$ & $w_{3} / \omega_{n 3}$ & $\xi_{3}$ & $\omega_{4} / \omega_{n 4}$ & $\xi_{4}$ \\
\hline 1 & 0.708 & 0.119 & - & - & - & - & - & - \\
\hline 2 & 0.875 & 0.096 & 0.731 & 0.037 & - & - & - & - \\
\hline 3 & 0.945 & 0.089 & 0.845 & 0.032 & 0.722 & 0.021 & - & - \\
\hline 4 & 0.983 & 0.086 & 0.901 & 0.029 & 0.832 & 0.0204 & 0.702 & 0.015 \\
\hline
\end{tabular}

Table 1. Summary of results of frequency response analysis of 1 ine 1. From the study of these results, it can be understood that the greater the number of lumps is, the better the agreement between the model and real line would be from the point of view of resonance frequencies. But the magnitude ratio at resonance becomes greater and greater due to the reduction of the damping coefficient corresponding to each resonance mode.

A representation of the line by 12 fluid lumps, not presented here, gave very good agreement with the experimental results on the level of frequencies of the first four resonance modes associated with considereable diveragence of magnitude ratio at resonance frequencies.

The validity of the model in the time domain is tested by the study of the line step response, for two different boundary conditions. In the first case, the line, with closed end, is excited by a step input pressure of 44,7 MPa magnitude, Fig. 5. The response of the pressure at the closed end to this excitation is evaluated experimental1y by LALLEMENT 171 . This response is evaluated theoretically by the computer simulation of the line. The simulation is realized by the exploitation of the equations describing the line, obtained from the band graph, for different numbers of fluid lumps. The experimental and theoretical results are presented in Fig. 10 and 11 .

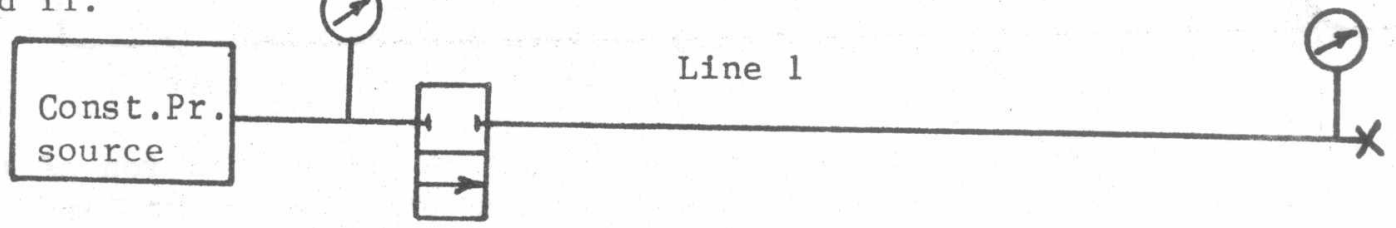

Fig.5. Configuration of the end pressure stepresponse measurement. 




Fig.10. Experimental and simulation results of the evaluation of the stop response of line l, with chased end, to a step input pressure, $n=1 \quad 2$.



Firfl1. Experimontal and simulation results of the evaluation of the step response of line 1 , with closed cnd, to a step input pressure, $n=3$ is 4 . 




Fig. 12. Experimental and simulation results of the evaluation of the step response of line 1 , with const. input pressure, to a sudden closing of its exit, $B e=19,610^{9} \mathrm{~Pa}, \mathrm{n}=1$ \& 2 .

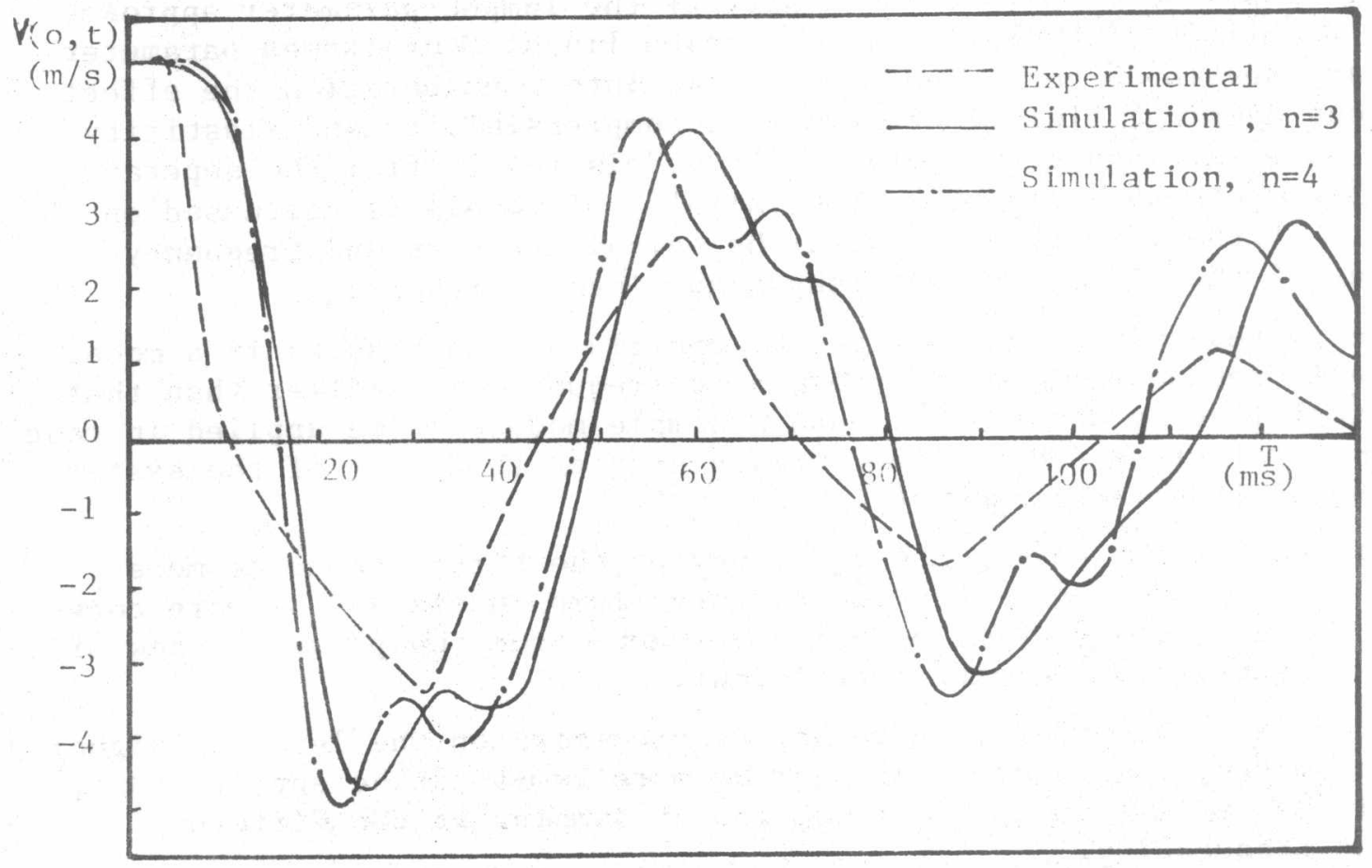

Fig. 13. Experimental and simulation results of the evaluation of the step response of line 1, with const, input pressure, to a sudden closing of its exit. $B e=19,5111^{9} \mathrm{~Pa}, \mathrm{n}=3 \& 4$. 
In this case, the response of the line is mainly due to the propagation of pressure waves. The variation of the flow results from the effect of fluid compressibility and deformation line walls. From figures 9 and 10 it $c$ an be seen that the model with one fluid lump presents slower oscillations and slightly greater damped response when compared with the experimental curve. The greater is the number of lumps, the better is the agreement between the simulation and experimental results. While the simulation results present slightly smaller damping for greater number of lumps. Similar results are obtaind in the second case, where the line, supplied by constant pressure is subjected to sudden closing of its end, Fig. 6. The response of the input speed to this sudden closure is evaluated experimentally $\mid 7$

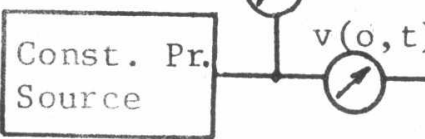

Fig.6. Configuration for the input speed step response measurement.

The sime response is evaluated theoretically for different number of lumps. The results are shown in figures 12 and 13. The study of these results shows also that the models with greater number of lumps have the responses in a good agreement with the experimental results, but the damping decreases with the increase of number of lumps.

\section{CONCLUSION}

This paper deals with the validity of the lumped paraneter approach for the modelling of hydraulic transmission lines. Four lumped parameter models are developed here. The models take into consideration the effect of viscous damping, fluid inertia, fluid compressibility and elasticity of line material. The simplicity of the models result from the seperate evaluation of these parameters. The validity of models is discussed on the basis of the comparison between the calculated step and frequency responses of the models and published experimental results.

The representation of the line by one fluid lump results in a model of a single resonance mode. Its resonance frequency is smaller than that of the real line by about $30 \%$. Such a simple model can be applied in case if the natural frequency of 1 ine is much greater than that of the system in which the line is integrated.

For the systems having the frequency of the first resonance mode near to that of the line, then two or three-lump models may be more convenient. These models present better precision from the point of view of natural frequency and damping coefficient.

If it is recommended to have better precision on the level of higher resonance modes, then a model of four or more lumps can be applied. But, we should pay attention to the reduction of damping at the different resonance frequencies.

\section{REFERENCES}

1. R. OLDENBERGER, "Mathematical Engineering Analysis", Dover, 1950.

2. R. OLDENBERGER and R.E. GOODSON, "Simplification of Hydraulic Line Dynamics By Using Infinite Product", ASME J. of Basic Eng., March 1964 , pp 1-8. 
3. A.F. D'SOUZA and R. OLDENBERGER, "Dynaic Response of Fluid Lines", ASME J. of Basic Eng., Sept 1964, pp 589-598.

4. J.T. KARAM, "A Simple But Complete Solution for step Response of a Semi-Infinite Circular Flud Transmission Line", ASME J. of Basic Eng., June 1972, pp 455-456.

5. R.E. GOODSON \& R.G. LEONARD, " A Survey of Modeling Techniques for Fluid Line Transients", ASME J. of Basic Eng., June 1972, pp 474-482.

6. D. KARNopP, "Bond Graph Models for Fluid Dynamic Systems", ASME J. of Dyn. Sys., Meas. and Control, Sept 1972, pp 222-229.

7. J. LALlement, ", Les Memoirs Techn. du Centre Technique des Industries Mecanique, Sen1is, France, No. 27, Sept 1976.

8. S. KATZ, " Transient Response of Fluid Lines By Frequency Response Conversion", ASME J. of Dyn. Sys., Meas. and Contro1, Dec 1977, pp $300-303$.

9. E.0. DOEBELIN, "System Modeling and Response, Theoritical and Experimental Approaches", J.W. 1980.

\section{NOMENCLATURE}

$a_{11}, a_{12}, a_{21} \& a_{22}$ Elements of transfer matrix.

A Transfer matrix.

B Bulk modulus of fluid, $\mathrm{N} / \mathrm{m}^{2}$.

Be Equivalent bulk modulus, $\mathrm{N} / \mathrm{m}^{2}$.

C Capacitance of line, $\mathrm{m}^{5} / \mathrm{N}$.

$\mathbb{C}$ Capacitance matrix.

D Inner diameter of line, m.

e Electric potential difference, Volt.

E Modulus of elasticity of pipe material, $\mathrm{N} / \mathrm{m}^{2}$.

F Force, N.

h Thickness of 1 ine walls, m.

i Electric current, A.

I Inertia of line, $\mathrm{Ns}^{2} / \mathrm{m}^{5}$.

II Inertia matrix.

$\mathrm{L}$ Total length of line, $m$.

$m$ Mass of fluid, $\mathrm{kg}$.

n Number of lumps.

$\mathrm{p}, \mathrm{p}_{\mathrm{O}}, \mathrm{p}_{1}, \mathrm{p}_{2} \& \mathrm{p}_{\mathrm{L}}$ Fluid pressure, $\mathrm{N} / \mathrm{m}^{2}$.

$\Delta \mathrm{P}_{\mathrm{R}}$ Pressure drop due to viscous friction, $\mathrm{N} / \mathrm{m}^{2}$.

$\Delta \mathrm{P}_{\mathrm{I}}^{\mathrm{R}}$ Accelerating pressure difference, $\mathrm{N} / \mathrm{m}^{2}$.

$Q_{0}^{\mathrm{L}}, \mathrm{Q}_{1}, \mathrm{Q}_{2} \& \mathrm{Q}_{\mathrm{L}}$ Flow rate, $\mathrm{m}^{3} / 3$.

$Q_{C} \quad$ Flow due to fluid compressibility, $\mathrm{m}^{3} / \mathrm{s}$

$\mathrm{R}^{\mathrm{C}}$ Resistance of line, $\mathrm{Ns} / \mathrm{m}^{5}$.

$\mathrm{R}_{\mathrm{e}}$ Reynolds number, ...

$\mathbb{R}$ Resistance matrix.

s Laplace's operator.

$t$ Time, $\mathrm{s}$.

V Fluid speed;m/s ${ }^{3}$

$\xi \quad$ Damping coefficient.

$\mu$ Dynamic viscosity of fluid, $\mathrm{Ns} / \mathrm{m}^{2}$ 
\begin{tabular}{|l|l|}
\hline DYN-4 & 46 \\
\hline
\end{tabular}



$\Gamma$

$\nu$ Kinematic viscosity of fluid, $\mathrm{m}^{2} / \mathrm{s}$.

$\rho$ Specefic mass of fluid, $\mathrm{Kg} / \mathrm{m}^{3}$.

$\lambda$ Friction coefficient.

$\omega$ Resonance frequency found out theoretically, $s^{-1}$

$\omega_{n}$ Resonance frequency found out experimentally; $\mathrm{s}^{-1}$ 